\title{
Methicillin-resistant Staphylococcus aureus in cystic fibrosis patients: do we need to care? A cohort study
}

\author{
Renata Wrobel Folescu Cohen', Tânia Wrobel Folescu", Pedro Daltro'", Marcia Cristina Bastos Boechat"', \\ Danielle Ferreira Limav ${ }^{v}$ Elizabeth Andrade Marques" ${ }^{v 1}$, Robson Souza Leão ${ }^{v 1}$ \\ Instituto Nacional de Saúde da Mulher da Criança e do Adolescente Fernandes Figueira, \\ Fundação Instituto Oswaldo Cruz (IFF/Fiocruz), Rio de Janeiro (RJ), Brazil
}

'Assistant Professor of Pediatrics, School of Medical Sciences, Universidade do Estado do Rio de Janeiro (UERJ), and Pediatric Pulmonologist, Instituto Nacional de Saúde da Mulher da Criança e do Adolescente Fernandes Figueira, Fundação Instituto Oswaldo Cruz

(IFF/Fiocruz), Rio de Janeiro (RJ), Brazil. "Head of Pediatric Pulmonology, Instituto Nacional de Saúde da Mulher da Criança e do Adolescente Fernandes Figueira, Fundação Instituto Oswaldo Cruz (IFF/Fiocruz), Rio de Janeiro (RJ), Brazil.

"'Radiologist, Instituto Nacional de Saúde da Mulher da Criança e do Adolescente Fernandes Figueira, Fundação Instituto Oswaldo Cruz (IFF/ Fiocruz), Rio de Janeiro (RJ), Brazil.

"Head of Radiology, Instituto Nacional de Saúde da Mulher da Criança e do Adolescente Fernandes Figueira, Fundação Instituto Oswaldo Cruz (IFF/Fiocruz), Rio de Janeiro (RJ), Brazil.

vFellow, Department of Microbiology, Immunology and Parasitology, School of Medical Sciences, Universidade do Estado do Rio de Janeiro (UERJ), Rio de Janeiro (RJ), Brazil. viprofessor, Department of Microbiology, Immunology and Parasitology, School of Medical Sciences, Universidade do Estado do Rio de Janeiro (UERJ), Rio de Janeiro (RJ), Brazil.

\section{KEY WORDS:}

Cystic fibrosis.

Methicillin-resistant Staphylococcus aureus.

Tomography.

Spirometry.

Body mass index

\begin{abstract}
CONTEXT AND OBJECTIVE: The prevalence of a variety of potentially pathogenic microorganisms in cystic fibrosis patients, such as methicillin-resistant Staphylococcus aureus (MRSA), has increased over the past decade. Given the increasing prevalence of MRSA and the few data available in the literature, better understanding of the clinical repercussions of colonization by this bacterium in cystic fibrosis patients becomes essential. This study aimed to evaluate the repercussions of chronic colonization by MRSA in cystic fibrosis patients. DESIGN AND SETTING: Retrospective cohort study from January 2004 to December 2013 in a cystic fibrosis reference center.

METHODS: Each patient with cystic fibrosis was evaluated for nutritional status (body mass index, BMI, and BMI percentile), pulmonary function and tomographic abnormalities (modified Bhalla scores) at the time of chronic colonization by MRSA or methicillin-susceptible Staphylococcus aureus (MSSA) and throughout the study period.

RESULTS: Twenty pairs of patients were included. There were no significant differences between the groups regarding nutritional characteristics. Spirometric data showed a trend towards greater obstruction of the airways in patients with MRSA. Patients with MRSA presented greater structural damage to their lungs, demonstrated not only by the total Bhalla score but also by its parameters individually.

CONCLUSIONS: Patients colonized by MRSA presented greater functional and structural respiratory impairment at the time of chronic colonization. Disease progression was also faster in patients chronically colonized by MRSA than in those with MSSA. This was shown through comparisons that avoided possible confounding variables.
\end{abstract}

\section{INTRODUCTION}

Bacterial respiratory infection starts early in cystic fibrosis $(\mathrm{CF})$ patients and Staphylococcus aureus (S. aureus) and Haemophilus influenzae are the main pathogens in young patients. ${ }^{1}$ Increasing life expectancy has led to higher prevalence of new pathogens in these patients, ${ }^{2}$ especially methicillinresistant S. aureus (MRSA). ${ }^{3}$ The prevalence of MRSA infection in CF patients in the United States rose from $2 \%$ in 2001 to $26.5 \%$ in $2014 .{ }^{4}$ While Pseudomonas aeruginosa and the Burkholderia cepacia complex are classically associated with respiratory deterioration and worsening of life expectancy, the clinical impact of MRSA colonization is not so clear. ${ }^{5}$

Since the clinical course of CF respiratory disease varies between patients, information that clearly depicts the conditions of the respiratory system and progression of pulmonary structural lesions is needed, especially among patients infected by MRSA. Nutritional status directly influences multisystemic involvement among CF patients and it has been considered that body mass index (BMI) is the most important parameter to be monitored. The association of better nutritional status with improved lung function is well documented and poor nutritional status with lower BMI is a risk factor for accelerated decline in lung function. ${ }^{6}$

Premature deaths continue to result directly or indirectly from loss of lung function. Therefore, spirometric measurements are important surrogate measures of disease progression, particularly forced expiratory volume in the first second $\left(\mathrm{FEV}_{1} \%\right)$ and predicted forced vital capacity (FVC\%). ${ }^{6}$

High-resolution computed tomography (HRCT) of the chest is a specific imaging method that can be used to evaluate early airway disease and parenchymal lesions. Furthermore, it has high 
sensitivity and specificity for diagnosing lung injury and also allows better qualitative description of respiratory impairment. ${ }^{78}$ HRCT results are presented as graphical images, which may be converted to score values that are useful for evaluating disease severity. Since the first proposal for creation of a computed tomography scoring system to quantify structural abnormalities in CF patients, ${ }^{9}$ other scoring systems have been described and been shown to be reproducible and comparable. ${ }^{7}$ The modified Bhalla score ${ }^{10}$ was shown to be reproducible and reliable, regardless of the severity of the lesions, which suggests that it is applicable in clinical practice for CF cases. ${ }^{11}$

\section{OBJECTIVE}

The aim of this study was to evaluate the clinical and tomographic impact of chronic MRSA infection in CF patients and compare these data with those from a group of individuals chronically colonized by methicillin-susceptible S. aureus (MSSA).

\section{METHODS}

This retrospective cohort study was conducted in the main CF center for children and adolescents in Rio de Janeiro, Brazil: the Fernandes Figueira National Institute for Women's, Children's and Adolescents' Health (Instituto Nacional de Saúde da Mulher, da Criança e do Adolescente Fernandes Figueira, Oswaldo Cruz Foundation, Ministry of Health), from January 2004 to December 2013. Approval was obtained from this institution's ethics committee (number CAAE 27902814.9.0000.5269).

In this institution, respiratory secretions (either sputum or throat swabs in the case of children under two years of age who were unable to provide sputum samples) were cultured in accordance with standardized protocols that had been established for CF patients. This was done on a three-monthly basis throughout the study. ${ }^{12}$

The inclusion criteria for the patients were that they needed to have a CF diagnosis in accordance with the Cystic Fibrosis Foundation consensus; ${ }^{13,14}$ undergo regular clinical and laboratory follow-up during the study period; and present chronic colonization with S. aureus (MSSA or MRSA) in respiratory secretions (three or more isolations over a 12 -month period). ${ }^{15,16}$ All patients that met eligibility criteria were consecutively included in the study and their data was recovered from medical records. Subjects who presented no respiratory colonization or were colonized with B. cepacia complex or presented intermittent colonization with $S$. aureus (less than three isolations over a 12-month period) were excluded from the study. No anti-staphylococcal prophylaxis is regularly used at this center. After the first isolation of MRSA (i.e. before chronic colonization), the patients underwent a course of antibiotics that included two weeks of rifampicin and trimethoprimsulfamethoxazole and five days of topical mupirocin.

Each of the 20 chronic MRSA patients was matched with a control (chronic MSSA CF patient) in accordance with the following criteria: gender, age, time of chronic colonization with $S$. aureus ( \pm 1 year) and chronic coinfection with $P$. aeruginosa. ${ }^{17}$

For each patient, medical record data were evaluated, including gender, age and pancreatic insufficiency (fecal fat or fecal elastase or need for exogenous replacement enzymes). The clinical outcome of each patient was also evaluated, considering the following parameters: BMI and BMI percentile for children over the age of two years, spirometric parameters such as predicted forced expiratory volume in the first minute $\left(\mathrm{FEV}_{1} \%\right)$ and predicted forced vital capacity (FVC\%), and modified Bhalla scores for HRCT. These parameters were evaluated and compared, at the time of chronic colonization with MRSA and MSSA, and throughout the study period.

Nutritional status was monitored through BMI obtained at the time of each evaluation at the CF center. The best annual BMI results were selected. These were used for BMI percentile calculations (for patients 2-19 years old) through the tool available at http://www.cdc.gov/healthyweight/assessing/bmi. ${ }^{18}$

Lung function data were evaluated through retrospective analysis on spirometric reports. The spirometric examinations were performed using the Collins Survey II computerized system (Warren E. Collins Inc., Massachusetts, USA), on patients over the age of six years who had the cognitive ability to undergo the test. The absolute values were converted to percentages of predicted values, using reference equations from Knudson et al. ${ }^{19}$ The highest $\mathrm{FEV}_{1} \%$ and FVC\% values reported for each patient every year were analyzed.

In this CF center, HRCT examinations were performed every two to four years when patients were clinically stable. These images were obtained using the ProSpeed-S ${ }^{\mathrm{m}}$ device (General Electric, Milwaukee, WI, USA), with $1 \mathrm{~mm}$ slices every $10 \mathrm{~mm}$, at 80 to $100 \mathrm{mAs}$ (milliampere/second) and $120 \mathrm{kV}$ (kilovolt), in windows of $-1500 \mathrm{HU}$ and at a level of $700 \mathrm{HU}$, without sedation, and with inspiration and expiration series. HRCT images were retrospectively analyzed by a pediatric radiologist and by a pulmonologist with more than 10 years of experience of $\mathrm{CF}$, who had no information about any patient data. After meeting and discussing the classification adopted for the modified Bhalla score, both professionals applied it to each exam in a completely random order. The modified Bhalla score had been previously validated at another study at this institution. ${ }^{11}$ The total score is obtained from the sum of the values for the severity and/or extent of each morphological abnormality and can range from 0 (no abnormality) to 37 (severe abnormalities in all items). ${ }^{10}$

\section{Statistical analysis}

Descriptive statistical analyses were performed through construction of tables and graphs and through summary measurements appropriate for each variable.

In order to study the trends of several variables over time, the annual rate of change was calculated by means of simple linear 
regression for each patient. The Wilcoxon nonparametric test was used to determine the statistical significance of differences between the MRSA and MSSA groups and between two moments. The Statistical Package for the Social Sciences (SPSS 17.0 for Windows) was used.

\section{RESULTS}

Out of 170 CF patients who were followed up at this CF center, $20(11.76 \%)$ fulfilled the criteria for chronic MRSA colonization. The comparison group was selected from among $70 \mathrm{CF}$ patients who presented chronic colonization with MSSA. Twenty pairs of patients were included: $40 \%$ were female (8 pairs); $95 \%$ had pancreatic insufficiency (19 pairs); and $25 \%$ had $P$. aeruginosa coinfection (5 pairs).

The mean age at the time when cystic fibrosis was diagnosed was 2.5 years in the MRSA group and 2.1 years in the MSSA group. Seven patients were diagnosed through newborn screening test and the others through clinical features compatible with cystic fibrosis, with confirmation using sweat test. The mean follow-up time at the CF center was similar in the two groups (6.7 years for MRSA versus 7 years for MSSA). Other sociodemographic data are available as supplementary material (Annex).

In relation to nutritional status, the mean BMI values at the time of chronic colonization were similar: 15.5 (standard deviation, $\mathrm{SD} \pm 2.2$ ) in the MRSA group and $15.6(\mathrm{SD} \pm 3.6)$ in the MSSA group, without significant statistical difference (P-value 0.823). The same trend was found for the mean BMI annual rate of change: $0.22(\mathrm{SD} \pm 0.49)$ in the MRSA group and $0.19(\mathrm{SD} \pm 0.44)$ in the MSSA group (P-value 0.852). Correspondingly, there was no statistically significant difference in BMI percentile between the time of chronic colonization (39.6 (SD \pm 32.3) in MRSA; 39.8 in MSSA ( $S D \pm 33.1)$; P-value 0.823) and thereafter: the mean annual rate of change in $\mathrm{BMI}$ percentile was $2(\mathrm{SD} \pm 8)$ in MRSA and 1.1 $(\mathrm{SD} \pm 6)$ in MSSA (P-value 0.852).

Spirometric data were available for 10 pairs of patients (who were older than six years of age). The mean values for $\mathrm{FEV}_{1} \%$ and $\mathrm{FVC} \%$ were lower in the MRSA group at the time of chronic colonization. After chronic colonization, the mean annual rate of decline in $\mathrm{FEV}_{1} \%$ for the MRSA group was $3.2 \%$ (SD \pm 1.8 ), while in MSSA it was $2.3 \%$ ( $\mathrm{SD} \pm 1.8$ ), but there was no statistically significant difference between the groups (P-value 0.374). Meanwhile, the mean annual rate of decline in FVC\% was also higher for the MRSA group (3.2\% per year, $\mathrm{SD} \pm 1.9$ ) than for the MSSA group (1.8\% per year ( $\mathrm{SD} \pm 1.7)$, with a statistically significant difference (P-value 0.038) (Table 1).

The modified Bhalla score results from HRCT at the time of chronic colonization are described in Table 2. Evaluation of each pair at the time of chronic colonization showed that the Bhalla scores were higher in 16 patients with MRSA. At this time, the mean Bhalla score in the MRSA group was twice the score in the MSSA group (6.5 and 3.3, respectively), with a statistically significant difference (P-value 0.002) (Table 2). The annual rate of change of the Bhalla score was higher in 19 patients with MRSA, thus showing that there was faster progression of lung injury in the MRSA group. The mean annual rate of change in Bhalla score was four times higher in the MRSA group (1.7 points per year in MRSA and 0.4 points per year in MSSA), with a statistically significant difference (P-value $<0.001)$ (Table 2).

Regarding the scores for each Bhalla parameter at the time of chronic colonization, only the findings of bronchiectasis and mucous plugging were more severe in the MRSA group. There were no statistically significant differences between the groups for the other parameters (Table 3 ). However, the HRCT performed after chronic colonization (mean time elapsed of 4.5 years) showed that all the Bhalla scores were significantly worse in the MRSA group (Table 4). At this time, all the MRSA patients presented air trapping, mosaic attenuation/perfusion pattern, bronchial wall thickening and mucous plugging. Bronchiectasis was found in $90 \%$ of the MRSA patients.

\section{DISCUSSION}

In the present study, careful pairing was done, considering age, gender and chronic colonization with $P$. aeruginosa, in order to eliminate confounding factors and effectively measure the impact of MRSA colonization in cystic fibrosis. It is known that there is a female survival disadvantage in $\mathrm{CF}$ cases $^{20}$ and that chronic $P$. aeruginosa infection results in a prolonged inflammatory response. The

Table 1. Spirometric data from patients with methicillin-resistant Staphylococcus aureus (MRSA) and methicillin-susceptible Staphylococcus aureus (MSSA): at the time of chronic colonization and mean annual rate of change after chronic colonization ( $n=10$ pairs)

\begin{tabular}{|c|c|c|c|c|c|c|c|c|}
\hline & \multicolumn{2}{|c|}{$\begin{array}{l}\mathrm{FEV}_{1} \% \text { at the time of } \\
\text { chronic colonization }\end{array}$} & \multicolumn{2}{|c|}{$\begin{array}{l}\text { Mean annual rate of } \\
\text { change in } \mathrm{FEV}_{1} \% \text { after } \\
\text { chronic colonization }\end{array}$} & \multicolumn{2}{|c|}{$\begin{array}{l}\text { FVC } \% \text { at the time of } \\
\text { chronic colonization }\end{array}$} & \multicolumn{2}{|c|}{$\begin{array}{l}\text { Mean annual rate of } \\
\text { change in FVC\% after } \\
\text { chronic colonization }\end{array}$} \\
\hline & MRSA & MSSA & MRSA & MSSA & MRSA & MSSA & MRSA & MSSA \\
\hline Standard deviation & 22.7 & 11.6 & 1.8 & 1.8 & 20.4 & 14.0 & 1.9 & 1.7 \\
\hline P-value (Wilcoxon test) & \multicolumn{2}{|c|}{0.005} & \multicolumn{2}{|c|}{0.374} & \multicolumn{2}{|c|}{0.047} & \multicolumn{2}{|c|}{0.038} \\
\hline
\end{tabular}

$\mathrm{FEV}, \%$ = predicted percentage forced expiratory volume in first second; $\mathrm{FVC} \%$ = predicted percentage forced vital capacity. 
latter is believed to cause respiratory tissue injury, which leads to progressive loss of lung function and adversely affects survival. ${ }^{21}$

Despite increasing prevalence of and morbidity associated with MRSA colonization in CF patients worldwide, little is known so far about its effects on lung damage. It is not clear whether MRSA colonization is simply a marker of greater severity of lung disease $^{5}$ or is an independent contributor towards lung function decline. ${ }^{15}$ In our study, the lung function data $\left(\mathrm{FEV}_{1} \%\right.$ and FVC\%) were worse at the time of chronic MRSA colonization. From then on, the annual decline in $\mathrm{FEV}_{1} \%$ was $39 \%$ higher in the MRSA group. These findings showed a trend towards worse outcomes, although without statistical significance, probably due to the sample size. They highlight the impact of chronic MRSA colonization on airflow obstruction in CF patients, compared with those who only had MSSA. These results are consistent with those from other studies in which MRSA was shown to have a negative impact on lung function. ${ }^{15,22}$ In a 10 -year longitudinal cohort study that included 17,357 patients in the United States, it was reported that the decline in lung function was faster among patients with chronic MRSA colonization, after adjustment for

Table 2. Bhalla score among patients with methicillin-resistant Staphylococcus aureus (MRSA) and methicillin-susceptible Staphylococcus aureus (MSSA): at the time of chronic colonization and mean annual rate of change after chronic colonization ( $n=20$ pairs)

\begin{tabular}{|c|c|c|c|c|}
\hline \multirow[t]{2}{*}{ Pair } & \multicolumn{2}{|c|}{$\begin{array}{l}\text { Bhalla score at } \\
\text { time of chronic } \\
\text { colonization }\end{array}$} & \multicolumn{2}{|c|}{$\begin{array}{c}\text { Annual rate of change } \\
\text { in Bhalla score }\end{array}$} \\
\hline & MRSA & MSSA & MRSA & MSSA \\
\hline 1 & 14 & 4 & 1.4 & 0.3 \\
\hline 2 & 4 & 2 & 0.8 & 0.1 \\
\hline 3 & 8 & 10 & 3.0 & 0.0 \\
\hline 4 & 5 & 5 & 0.6 & 0.2 \\
\hline 5 & 4 & 6 & 2.4 & -0.6 \\
\hline 6 & 9 & 8 & 0.4 & 0.5 \\
\hline 7 & 3 & 1 & 2.8 & 0.7 \\
\hline 8 & 10 & 4 & 1.2 & 0.7 \\
\hline 9 & 8 & 1 & 1.7 & 0.0 \\
\hline 10 & 4 & 3 & 1.8 & 0.2 \\
\hline 11 & 7 & 6 & 2.0 & 0.6 \\
\hline 12 & 3 & 0 & 2.0 & 1.1 \\
\hline 13 & 4 & 0 & 0.8 & 0.2 \\
\hline 14 & 4 & 2 & 0.8 & 0.3 \\
\hline 15 & 5 & 6 & 1.8 & 0.6 \\
\hline 16 & 4 & 0 & 2.4 & 1.0 \\
\hline 17 & 4 & 0 & 2.5 & 0.4 \\
\hline 18 & 4 & 0 & 1.9 & 0.5 \\
\hline 19 & 14 & 4 & 1.1 & 0.5 \\
\hline 20 & 12 & 3 & 2.4 & 0.6 \\
\hline Mean & 6.5 & 3.3 & 1.7 & 0.4 \\
\hline Standard deviation & 3.6 & 2.9 & 0.8 & 0.4 \\
\hline $\begin{array}{l}\text { P-value } \\
\text { (Wilcoxon test) }\end{array}$ & \multicolumn{2}{|c|}{0.002} & \multicolumn{2}{|c|}{$<0.001$} \\
\hline
\end{tabular}

possible confounding variables. In that cohort, the decline in predicted $\mathrm{FEV}_{1}$ of $2.06 \%$ /year was $43 \%$ more rapid than the $1.44 \%$ predicted/year among those without MRSA (P-value < 0.001). ${ }^{15}$ Ren et al., using a large database of CF patients, showed that out of 1834 patients presenting $S$. aureus in respiratory tract cultures, those who were less than 18 years of age and had MRSA showed significantly greater airflow obstruction $\left(\mathrm{FEV}_{1}\right)$, compared with

Table 3. Number of patients with each score for the different parameters at the time of chronic colonization in the methicillinresistant Staphylococcus aureus (MRSA) and methicillin-susceptible Staphylococcus aureus (MSSA) groups ( $n=20$ pairs)

\begin{tabular}{|c|c|c|c|c|c|c|c|}
\hline \multirow{2}{*}{ Parameter } & \multirow{2}{*}{$\begin{array}{l}\text { MRSA group } \\
\text { score }\end{array}$} & \multicolumn{5}{|c|}{ MSSA group score } & \multirow{2}{*}{ P-value* } \\
\hline & & Total & 0 & 1 & 2 & 3 & \\
\hline \multirow{5}{*}{$\begin{array}{l}\text { Severity of } \\
\text { bronchiectasis }\end{array}$} & 0 & 10 & 10 & 0 & 0 & 0 & \multirow{5}{*}{0.063} \\
\hline & 1 & 8 & 3 & 5 & 0 & 0 & \\
\hline & 2 & 2 & 2 & 0 & 0 & 0 & \\
\hline & 3 & 0 & 0 & 0 & 0 & 0 & \\
\hline & Total & 20 & 15 & 5 & 0 & 0 & \\
\hline \multirow{5}{*}{$\begin{array}{l}\text { Peribronchial } \\
\text { thickening }\end{array}$} & 0 & 2 & 1 & 1 & 0 & 0 & \multirow{5}{*}{0.092} \\
\hline & 1 & 16 & 6 & 9 & 1 & 0 & \\
\hline & 2 & 2 & 1 & 1 & 0 & 0 & \\
\hline & 3 & 0 & 0 & 0 & 0 & 0 & \\
\hline & Total & 20 & 8 & 11 & 1 & 0 & \\
\hline \multirow{5}{*}{$\begin{array}{l}\text { Extent of } \\
\text { bronchiectasis }\end{array}$} & 0 & 10 & 10 & 0 & 0 & 0 & \multirow{5}{*}{0.031} \\
\hline & 1 & 5 & 1 & 4 & 0 & 0 & \\
\hline & 2 & 4 & 3 & 1 & 0 & 0 & \\
\hline & 3 & 1 & 1 & 0 & 0 & 0 & \\
\hline & Total & 20 & 15 & 5 & 0 & 0 & \\
\hline \multirow{5}{*}{$\begin{array}{l}\text { Extent of } \\
\text { mucous } \\
\text { plugging }\end{array}$} & 0 & 10 & 9 & 1 & 0 & 0 & \multirow{5}{*}{0.035} \\
\hline & 1 & 7 & 5 & 2 & 0 & 0 & \\
\hline & 2 & 3 & 1 & 2 & 0 & 0 & \\
\hline & 3 & 0 & 0 & 0 & 0 & 0 & \\
\hline & Total & 20 & 15 & 5 & 0 & 0 & \\
\hline \multirow{5}{*}{$\begin{array}{l}\text { Generation } \\
\text { of bronchial } \\
\text { divisions }\end{array}$} & 0 & 10 & 10 & 0 & 0 & 0 & \multirow{5}{*}{0.063} \\
\hline & 1 & 6 & 2 & 4 & 0 & 0 & \\
\hline & 2 & 3 & 2 & 0 & 1 & 0 & \\
\hline & 3 & 1 & 1 & 0 & 0 & 0 & \\
\hline & Total & 20 & 15 & 4 & 1 & 0 & \\
\hline \multirow{4}{*}{$\begin{array}{l}\text { Collapse/ } \\
\text { consolidation }\end{array}$} & 0 & 8 & 5 & 0 & 3 & & \multirow{4}{*}{0.212} \\
\hline & 1 & 9 & 9 & 0 & 0 & & \\
\hline & 2 & 3 & 2 & 1 & 0 & & \\
\hline & Total & 20 & 16 & 1 & 3 & & \\
\hline \multirow{4}{*}{$\begin{array}{l}\text { Mosaic } \\
\text { perfusion }\end{array}$} & 0 & 4 & 2 & 2 & 0 & & \multirow{4}{*}{0.146} \\
\hline & 1 & 14 & 7 & 6 & 1 & & \\
\hline & 2 & 2 & 0 & 2 & 0 & & \\
\hline & Total & 20 & 9 & 10 & 1 & & \\
\hline \multirow{4}{*}{ Air trapping } & 0 & 0 & 2 & 2 & 0 & & \multirow{4}{*}{0.146} \\
\hline & 1 & 14 & 7 & 6 & 1 & & \\
\hline & 2 & 2 & 0 & 2 & 0 & & \\
\hline & Total & 20 & 9 & 10 & 1 & & \\
\hline
\end{tabular}

*P-value obtained via Wilcoxon test.

Note: The items "sacculations/abscesses"; "emphysema"; "acinar nodule"; "thickening of intralobular septa" and "ground glass" were not analyzed individually because almost all scores were zero. 
MSSA patients. ${ }^{22}$ However, their study did not match patients according to age and gender, which are significant confounders and could have influenced the outcome. Despite the knowledge that the rate of transient infection with MRSA can reach up to $69 \%,{ }^{15}$ patients with only one positive culture could still be included in the MRSA group in their study. ${ }^{22}$ Our study provides

Table 4. Number of patients with each score for the different parameters after ${ }^{*}$ chronic colonization in the methicillin-resistant Staphylococcus aureus (MRSA) and methicillin-susceptible Staphylococcus aureus (MSSA) groups ( $n=20$ pairs)

\begin{tabular}{|c|c|c|c|c|c|c|c|}
\hline \multirow[b]{2}{*}{ Parameter } & \multirow{2}{*}{$\begin{array}{l}\text { MRSA } \\
\text { group } \\
\text { score }\end{array}$} & \multirow[b]{2}{*}{ Total } & \multicolumn{4}{|c|}{ MSSA group score } & \multirow[b]{2}{*}{ P-value $* *$} \\
\hline & & & 0 & 1 & 2 & 3 & \\
\hline \multirow{5}{*}{$\begin{array}{l}\text { Severity of } \\
\text { bronchiectasis }\end{array}$} & 0 & 2 & 2 & 0 & 0 & 0 & \multirow{5}{*}{$<0.001$} \\
\hline & 1 & 8 & 5 & 2 & 1 & 0 & \\
\hline & 2 & 3 & 2 & 0 & 1 & 0 & \\
\hline & 3 & 7 & 2 & 4 & 1 & 0 & \\
\hline & Total & 20 & 11 & 6 & 3 & 0 & \\
\hline \multirow{5}{*}{$\begin{array}{l}\text { Peribronchial } \\
\text { thickening }\end{array}$} & 0 & 0 & 0 & 0 & 0 & 0 & \multirow{5}{*}{0.004} \\
\hline & 1 & 8 & 0 & 7 & 1 & 0 & \\
\hline & 2 & 9 & 1 & 7 & 1 & 0 & \\
\hline & 3 & 3 & 0 & 3 & 0 & 0 & \\
\hline & Total & 20 & 1 & 17 & 2 & 0 & \\
\hline \multirow{5}{*}{$\begin{array}{l}\text { Extent of } \\
\text { bronchiectasis }\end{array}$} & 0 & 2 & 2 & 0 & 0 & 0 & \multirow{5}{*}{0.001} \\
\hline & 1 & 7 & 5 & 1 & 1 & 0 & \\
\hline & 2 & 4 & 1 & 0 & 3 & 0 & \\
\hline & 3 & 7 & 3 & 3 & 1 & 0 & \\
\hline & Total & 20 & 11 & 4 & 5 & 0 & \\
\hline \multirow{5}{*}{$\begin{array}{l}\text { Extent of } \\
\text { mucous } \\
\text { plugging }\end{array}$} & 0 & 0 & 0 & 0 & 0 & 0 & \multirow{5}{*}{0.001} \\
\hline & 1 & 12 & 6 & 5 & 1 & 0 & \\
\hline & 2 & 4 & 4 & 0 & 0 & 0 & \\
\hline & 3 & 4 & 1 & 2 & 1 & 0 & \\
\hline & Total & 20 & 11 & 7 & 2 & 0 & \\
\hline \multirow{5}{*}{$\begin{array}{l}\text { Generation } \\
\text { of bronchial } \\
\text { divisions }\end{array}$} & 0 & 3 & 3 & 0 & 0 & 0 & \multirow{5}{*}{$<0.001$} \\
\hline & 1 & 4 & 2 & 2 & 0 & 0 & \\
\hline & 2 & 5 & 4 & 0 & 1 & 0 & \\
\hline & 3 & 8 & 3 & 3 & 2 & 0 & \\
\hline & Total & 20 & 12 & 5 & 3 & 0 & \\
\hline \multirow{4}{*}{$\begin{array}{l}\text { Collapse/ } \\
\text { consolidation }\end{array}$} & 0 & 4 & 4 & 0 & 0 & & \multirow{4}{*}{$<0.001$} \\
\hline & 1 & 12 & 10 & 2 & 0 & & \\
\hline & 2 & 4 & 2 & 2 & 0 & & \\
\hline & Total & 20 & 16 & 4 & 0 & & \\
\hline \multirow{4}{*}{$\begin{array}{l}\text { Mosaic } \\
\text { perfusion }\end{array}$} & 0 & 0 & 0 & 0 & 0 & & \multirow{4}{*}{$<0.001$} \\
\hline & 1 & 10 & 3 & 7 & 0 & & \\
\hline & 2 & 10 & 3 & 6 & 1 & & \\
\hline & Total & 20 & 6 & 13 & 1 & & \\
\hline \multirow{4}{*}{ Air trapping } & 0 & 0 & 0 & 0 & 0 & & \multirow{4}{*}{$<0.001$} \\
\hline & 1 & 10 & 3 & 7 & 0 & & \\
\hline & 2 & 10 & 3 & 6 & 1 & & \\
\hline & Total & 20 & 6 & 13 & 1 & & \\
\hline
\end{tabular}

*Mean time elapsed of 4.5 years; ${ }^{* *}$-value obtained via Wilcoxon test. Note: The items "sacculations/abscesses"; "emphysema"; "acinar nodule"; "thickening of intralobular septa" and "ground glass" were not analyzed individually because almost all scores were zero. consistent data, in that it only included patients with chronic MRSA colonization, so as to provide better understanding of the lung function repercussions of this bacterium.

Lung function data (especially $\mathrm{FEV}_{1} \%$ ) and the respiratory exacerbation rate have been widely used as sensitive markers. However, since advances in CF treatment have been able to delay the loss of lung function, other measurements have been revealed to be important for monitoring CF patients, including nutritional indices such as BMI. ${ }^{6}$ The association of better nutritional status with improved lung function is well documented, and poor nutrition is a risk factor for accelerated decline in lung function. Data from 6,835 CF patients in the German CF Registry (1995-2005) found that low BMI $\left(<19 \mathrm{~kg} / \mathrm{m}^{2}\right)$ and low $\mathrm{FEV}_{1}(<80 \%)$ correlated with mortality. ${ }^{6}$ Identifying risk factors that may contribute to the rate of decline of lung function and BMI may help in focusing interventions. ${ }^{6}$ Few studies have discussed the effects of MRSA colonization on nutritional status. A retrospective study (2003-2007) identified 12 pediatric patients presenting MRSA colonization. After one year of MRSA colonization, only one patient showed a decrease in BMI percentile. ${ }^{23}$ In our study, there were no significant differences between the groups regarding BMI or BMI percentile at the time of chronic MRSA colonization, or in the annual rate of decline of BMI.

With the recent advances in therapeutic approaches towards $\mathrm{CF}$, it is essential to identify tools that can monitor lung disease progression and response to treatment. ${ }^{7}$ Imaging examinations are able to detect early disease progression, thereby contributing to treatment effectiveness and quality of life among CF patients. Furthermore, HRCT can be used both for patients who are unable to undergo spirometry and for analysis on the two tests, since HRCT shows early changes in patients with normal spirometry. ${ }^{24}$ Several studies have shown that despite stable spirometric parameters, HRCT scores show annual progression in total CT score. ${ }^{7}$ Despite the well-established importance of HRCT scores for CF, few studies have made reference to these scores in different microbiological groups, ${ }^{11}$ with no published data regarding MRSA colonized patients. In this context, our study highlights the importance of HRCT scores in CF patients with chronic colonization with MRSA, thus making a significant contribution towards aiding clinicians who deal with this group of patients.

The importance of certain lung morphological abnormalities is emphasized in the modified Bhalla scoring system. The parameter "mucous plugs", for example, is scored separately because of their crucial role in the pathogenesis of bronchiectasis. Likewise, peribronchial thickening reflects the presence of recurrent chronic infection that results in bronchial and peribronchial inflammation and/or fibrosis, which should be scored separately. These two abnormalities are of great importance in managing CF, since they might suggest 
the need for a specific therapeutic approach. ${ }^{9}$ Simultaneously, presence of bronchiectasis in CF cases has been correlated with chronic bronchial disease, consequent to persistent inflammation and subsequent weakening of the airway wall, thereby resulting in irreversible distension of the bronchial walls. ${ }^{25}$

The importance of these considerations stood out in the present study, from which it was evident that abnormalities such as bronchiectasis, peribronchial thickening and mucous plug formation were present in almost all patients with chronic MRSA colonization. These results are concordant with analyses from other studies in which the three most prevalent abnormalities were bronchiectasis (86-90\%), peribronchial thickening (53-80\%) and mucous plugging (63-79\%). ${ }^{11,26-28}$

In the present study, the modified Bhalla score values demonstrated that MRSA patients showed greater structural lung damage at the time of chronic colonization. At that time, detailed analysis on each parameter of the Bhalla score showed that for two of them, there were statistically significant differences between the groups (extent of bronchiectasis and mucous plugging). After chronic MRSA colonization, there was marked progression of structural lung damage, as demonstrated through the total modified Bhalla score and all its parameters individually. The presence of bronchiectasis in all patients with chronic MRSA colonization highlights the severity of injuries in this group and confirms the association of MRSA colonization with progression of structural lung injury in CF patients.

Although the other more prevalent injuries, such as peribronchial thickening, mucous plugging and mosaic perfusion, are known to be reversible, these were also more frequent in the MRSA group. This evidence supports the hypothesis that chronic MRSA colonization leads to a more prominent inflammatory response and earlier structural lesions. The mechanisms proposed for this effect may be similar to those proposed for MRSA pneumonia in nonCF patients. It is possible that MRSA remains in the respiratory tract for longer times because of its resistance to commonly used antibiotics. Moreover, presence of toxins and virulence factors may mediate greater degrees of airway inflammation..$^{29,30}$

The present study is unprecedented in Brazil. It determined the relationship between clinical data and chronic colonization with MRSA, an emergent bacterium in CF cases for which greater understanding of the impact of chronic infection is needed. However, the present study has limitations because of its retrospective nature and small sample size, especially in relation to lung function tests, and these may have interfered with the statistical significance of the results. Despite these limitations, the implications of our findings strengthen the argument for development of possible evidence-based MRSA eradication measures and serve as a starting point for future studies on CF patients with chronic MRSA colonization.

\section{CONCLUSION}

These MRSA-colonized CF patients presented greater degrees of functional and structural lung disease at the time of chronic colonization, and disease progression seemed to be faster. This was shown through comparisons in which potential confounding variables were controlled for.

\section{REFERENCES}

1. Gibson RL, Burns JL, Ramsey BW. Pathophysiology and management of pulmonary infections in cystic fibrosis. Am J Resp Crit Care Med 2003;168(8):918-51.

2. Dasenbrook EC. Update on methicillin-resistant Staphylococcus aureus in cystic fibrosis. Curr Opin Pulm Med. 2011;17(6):437-41.

3. Dasenbrook EC, Checkley W, Merlo CA, et al. Association between respiratory tract methicillin-resistant Staphylococcus aureus and survival in cystic fibrosis. JAMA. 2010;303(23):2386-92.

4. Cystic Fibrosis Foundation Patient Registry. 2014 Annual Data Report. Bethesda: Cystic Fibrosis Foundation; 2015. Available from: https://www. cff.org/2014_CFF_Annual_Data_Report_to_the_Center_Directors.pdf/. Accessed in 2017 (May 2).

5. Sawicki GS, Rasouliyan L, Pasta DJ, et al. The impact of incident methicillin resistant Staphylococcus aureus detection on pulmonary function in cystic fibrosis. Pediatr Pulmonol. 2008;43(11):1117-23.

6. Zemanick ET, Harris JK, Conway S, et al. Measuring and improving respiratory outcomes in cystic fibrosis lung disease: opportunities and challenges to therapy. J Cyst Fibros. 2010;9(1):1-16.

7. Loeve M, Krestin GP, Rosenfeld M, et al. Chest computed tomography: a validated surrogate endpoint of cystic fibrosis lung disease? Eur Respir J. 2013;42(3):844-57.

8. Tiddens HA. Chest computed tomography scans should be considered as a routine investigation in cystic fibrosis. Paediatr Respir Rev. 2006;7(3):202-8.

9. Bhalla M, Turcios N, Aponte V, et al. Cystic fibrosis: scoring system with thin-section CT. Radiology. 1991;179(3):783-8

10. Judge EP, Dodd JD, Masterson JB, Gallagher CG. Pulmonary abnormalities on high-resolution CT demonstrate more rapid decline than FEV1 in adults with cystic fibrosis. Chest. 2006;130(5):1424-32.

11. Folescu TW, Marques EA, Boechat MC, et al. Escore tomográfico em pacientes com fibrose cística colonizados por Pseudomonas aeruginosa ou Staphylococcus aureus [High-resolution computed tomography scores in cystic fibrosis patients colonized with Pseudomonas aeruginosa or Staphylococcus aureus]. J Bras Pneumol. 2012;38(1):41-9.

12. Gilligan PH, Kiska DL, Appleman MD. Cumitech 43: Cystic fibrosis microbiology. Washington: ASM Press; 2006.

13. Rosenstein BJ, Cutting GR. The diagnosis of cystic fibrosis: a consensus statement. Cystic Fibrosis Foundation Consensus Panel. J Pediatr. 1998;132(4):589-95.

14. Farrell PM, Rosenstein BJ, White TB, et al. Guidelines for diagnosis of cystic fibrosis in newborns through older adults: Cystic Fibrosis Foundation consensus report. J Pediatr. 2008;153(2):S4-S14. 
15. Dasenbrook EC, Merlo CA, Diener-West M, Lechtzin N, Boyle MP. Persistent methicillin-resistant Staphylococcus aureus and rate of FEV1 decline in cystic fibrosis. Am J Respir Crit Care Med. 2008;178(8):814-21.

16. Cox DW, Kelly C, Rush R, et al. The impact of MRSA infection in the airways of children with cystic fibrosis; a case-control study. Ir Med J. 2011;104(10):305-8

17. Vanderhelst $E$, De Meirleir $L$, Verbanck S, et al. Prevalence and impact on FEV(1) decline of chronic methicillin-resistant Staphylococcus aureus (MRSA) colonization in patients with cystic fibrosis. A single-center, case control study of 165 patients. J Cyst Fibros. 2012;11(1):2-7.

18. Centers for Disease Control and Prevention. BMI Percentile Calculator for Child and Teen. Available from: https://nccd.cdc.gov/dnpabmi/ calculator.aspx. Accessed in 2017 (May 2).

19. Knudson RJ, Lebowitz MD, Holberg CJ, Burrows B. Changes in the normal maximal expiratory flow-volume curve with growth and aging. Am Rev Respir Dis. 1983;127(6):725-34.

20. Mehta G, Macek M Jr, Mehta A; European Registry Working Group. Cystic fibrosis across Europe: EuroCareCF analysis of demographic data from 35 countries. J Cyst Fibros. 2010;9 Suppl 2:S5-S21.

21. Emerson J, Rosenfeld M, McNamara S, Ramsey B, Gibson RL. Pseudomonas aeruginosa and other predictors of mortality and morbidity in young children with cystic fibrosis. Pediatr Pulmonol. 2002;34(2):91-100

22. Ren CL, Morgan WJ, Konstan MW, et al. Presence of methicillin resistant Staphylococcus aureus in respiratory cultures from cystic fibrosis patients is associated with lower lung function. Pediatr Pulmonol. 2007:42(6):513-8.

23. Fermeiro J, Reis $P$, Castanhinha S, Pereira L, Barreto $C$. The impact of methicillin-resistant Staphylococcus aureus colonisation on paediatric cystic fibrosis patients'morbidity. Rev Port Pneumol. 2010;16(4):527-42.

24. Pereira FFL, Camargos PAM, Ibiapina CC, et al. Correlação entre escore de Bhalla e espirometria em crianças e adolescentes com fibrose cística [Correlation between Bhalla score and spirometry in children and adolescents with Cystic Fibrosis]. Rev Assoc Med Bras (1992). 2014;60(3):216-21.

25. Taccone A, Romano L, Marzoli A, et al. High-resolution computed tomography in cystic fibrosis. Eur J Radiol. 1992;15(2):125-9.

26. Santamaria F, Grillo G, Guidi G, et al. Cystic fibrosis: when should highresolution computed tomography of the chest Be obtained? Pediatrics. 1998:101(5):908-13.

27. Helbich TH, Heinz-Peer G, Eichler I, et al. Cystic fibrosis: CT assessment of lung involvement in children and adults. Radiology. 1999;213(2):537-44.

28. de Jong PA, Ottink MD, Robben SG, et al. Pulmonary disease assessment in cystic fibrosis: comparison of CT scoring systems and value of bronchial and arterial dimension measurements. Radiology. 2004;231(2):434-9.

29. Zetola N, Francis JS, Nuermberger EL, Bishai WR. Community-acquired methicillin-resistant Staphylococcus aureus: an emerging threat. Lancet Infect Dis. 2005;5(5):275-86.
30. Gonzalez BE, Hulten KG, Dishop MK, et al. Pulmonary manifestations in children with invasive community-acquired Staphylococcus aureus infection. Clin Infect Dis. 2005;41(5):583-90.

Acknowledgements: We would like to thank Ronir Raggio, who helped with statistical analysis

Sources of funding: This research did not receive any funding

Conflict of interest: The authors declare that they did not have any conflict of interests

Date of first submission: December 22, 2016

Last received: March 10, 2017

Accepted: March 24, 2017

\section{Address for correspondence:}

Renata Wrobel Folescu Cohen

Departamento de Pneumologia Pediátrica, Instituto Nacional de Saúde da Mulher da Criança e do Adolescente Fernandes Figueira, Fundação Oswaldo Cruz, Ministério da Saúde

Av. Rui Barbosa, 716 - 2o andar

Flamengo — Rio de Janeiro (RJ) — Brasil

CEP 22250-020

Tel. (+55 21) 2554-1770

E-mail: renatawfc@gmail.com 
Annex. Pairing between patients with methicillin-resistant Staphylococcus aureus (MRSA) and methicillin-susceptible Staphylococcus aureus (MSSA) according to gender, age, time of chronic colonization with $S$. aureus and chronic coinfection with $P$. aeruginosa

\begin{tabular}{|c|c|c|c|c|c|}
\hline Pair & & Gender & Birth date & $\begin{array}{c}\text { Chronic } \\
\text { colonization } \\
\text { with S. aureus }\end{array}$ & $\begin{array}{c}\text { Colonization } \\
\text { with } P \text {. } \\
\text { aeruginosa }\end{array}$ \\
\hline \multirow{2}{*}{1} & MRSA & $\mathrm{F}$ & May 21, 2007 & 2009 & No \\
\hline & MSSA & $\mathrm{F}$ & $\operatorname{Dec} 17,2007$ & 2009 & No \\
\hline \multirow{2}{*}{2} & MRSA & $\mathrm{F}$ & Jul 11, 2003 & 2009 & No \\
\hline & MSSA & $\mathrm{F}$ & Nov 3, 2003 & 2010 & No \\
\hline \multirow{2}{*}{3} & MRSA & $\mathrm{F}$ & Sep 4, 2009 & 2012 & No \\
\hline & MSSA & $\mathrm{F}$ & Mar 9, 2008 & 2011 & No \\
\hline \multirow{2}{*}{4} & MRSA & M & Oct 27, 1997 & 2007 & No \\
\hline & MSSA & M & Dec 10, 1996 & 2008 & No \\
\hline \multirow{2}{*}{5} & MRSA & M & May 24, 2011 & 2012 & No \\
\hline & MSSA & M & Jul 20, 2011 & 2012 & No \\
\hline \multirow{2}{*}{6} & MRSA & $\mathrm{F}$ & Jan 15, 1996 & 2006 & Yes \\
\hline & MSSA & $\mathrm{F}$ & Feb 18, 1998 & 2007 & Yes \\
\hline \multirow{2}{*}{7} & MRSA & M & Nov 28, 2007 & 2009 & No \\
\hline & MSSA & M & Feb 15, 2007 & 2009 & No \\
\hline \multirow{2}{*}{8} & MRSA & $\mathrm{F}$ & Oct 7, 1998 & 2010 & Yes \\
\hline & MSSA & $\mathrm{F}$ & Jul 31, 1998 & 2007 & Yes \\
\hline \multirow{2}{*}{9} & MRSA & M & Jul 13, 2006 & 2011 & No \\
\hline & MSSA & M & Jul 2, 2006 & 2012 & No \\
\hline \multirow{2}{*}{10} & MRSA & M & Sep 23, 2006 & 2011 & No \\
\hline & MSSA & M & Jun 28, 2006 & 2010 & No \\
\hline \multirow{2}{*}{11} & MRSA & M & Aug 29, 1995 & 2008 & No \\
\hline & MSSA & M & Nov 6, 1997 & 2010 & No \\
\hline \multirow{2}{*}{12} & MRSA & $\mathrm{F}$ & Nov 30, 2006 & 2008 & No \\
\hline & MSSA & $\mathrm{F}$ & Sep 15, 2008 & 2010 & No \\
\hline \multirow{2}{*}{13} & MRSA & M & Aug 20, 1995 & 2009 & No \\
\hline & MSSA & M & Aug 1, 1996 & 2009 & No \\
\hline \multirow{2}{*}{14} & MRSA & M & Apr 2, 2008 & 2009 & No \\
\hline & MSSA & M & Feb 20, 2009 & 2010 & No \\
\hline \multirow{2}{*}{15} & MRSA & M & May 12,2000 & 2010 & Yes \\
\hline & MSSA & M & Nov 28,2000 & 2008 & Yes \\
\hline \multirow{2}{*}{16} & MRSA & M & Jan 11, 2006 & 2007 & No \\
\hline & MSSA & M & Jul 7, 2004 & 2007 & No \\
\hline \multirow{2}{*}{17} & MRSA & M & Feb 27, 2009 & 2010 & No \\
\hline & MSSA & M & Feb 9, 2009 & 2010 & No \\
\hline \multirow{2}{*}{18} & MRSA & $\mathrm{F}$ & $\operatorname{Dec}$ 3, 2011 & 2012 & No \\
\hline & MSSA & $\mathrm{F}$ & Jul 14, 2011 & 2012 & No \\
\hline \multirow{2}{*}{19} & MRSA & $\mathrm{F}$ & Dec 28, 2001 & 2008 & Yes \\
\hline & MSSA & $\mathrm{F}$ & Jun 1, 2000 & 2007 & Yes \\
\hline \multirow{2}{*}{20} & MRSA & M & Sep 1, 1996 & 2011 & Yes \\
\hline & MSSA & $M$ & Nov 10, 1996 & 2007 & Yes \\
\hline
\end{tabular}

